\title{
Give Hippocrates a jersey: promoting health through football/sport
}

\author{
$\underset{\substack{\text { EDITOR's } \\ \text { CHOICE }}}{v i r i ~ D v o r a ́ k ~}$
}

As sports physicians, we follow the Hippocratic Oath and support the philosophy: no borders, no colour, no politics, no constraints - exercise for fun with the objective of improving physical and mental fitness.

\section{HIPPOCRATES}

During the Olympic Games 2004 in Athens, many of us had the opportunity to remind ourselves of the historical perspectives of medicine while visiting sites associated with the father of medicine, Hippocrates (460-377BC); highlights included the Acropolis and his birth and place of work on the island of Kos. While visiting those places and recalling the achievements of Hippocrates, it is appropriate to reflect on the Hippocratic Oath, which we physicians still follow today when we fulfil our duties according to the ethical principles of our profession.

The Hippocratic Oath begins with the following sentence: "I swear by Apollo, Aesculapius, Hygeia, and Panacea...". To understand the meaning of the commitment undertaken by all physicians, we have to understand the hierarchy of the gods at that time, which led to the "Ancient healthcare management" ( $T$ Drobny, 2006, personal communication, fig 1).

Apollo, the physician, was the son of Zeus and, as was the custom at that time, he declared his son Aesculapius the God of Medicine. Aesculapius called his first-born daughter Hygeia, the Goddess of Health and his second daughter Panacea, the Goddess of Cures. Aesculapius understood the principle and the importance of prevention, and considered the maintenance of good health to be more important than developing cures. Therefore, when taking the Hippocratic Oath, we physicians should be aware that we swear first to Hygeia, so our first objective should be to maintain health and prevent diseases and injuries of those we look after.

Correspondence to: Professor Jiri Dvorak, FIFA Medical Centre of Excellence, Schulthess Clinic, Lengghalde 2, 8008 Zurich, Switzerland; jiri.dvorak@ kws.ch
The Hippocratic Oath ends with the following sentence: "If, therefore, I observe this oath and do not violate it, may I prosper both in my life and in my profession, earning good repute among all men for all time". We can interpret this today to mean that if we observe the oath and accordingly make prevention our prime objective, we should not only earn social repute among sports politicians and executives but also achieve appropriate support to fulfil the objective of preserving the health of the athletes we care for irrespective of their gender, age and level of skills, as outlined in the ancient healthcare management system. Nothing should be more important for each international sports federation than to state that the sport's objective is to preserve or improve the health condition of the general population. This was eloquently summarised by Booth and Roberts, ${ }^{1}$ who showed that staying active reduced the risks of chronic disease.

\section{AIM OF SCIENCE}

Friedrich Schiller (1759-1805), a German writer and philosopher, a close friend of

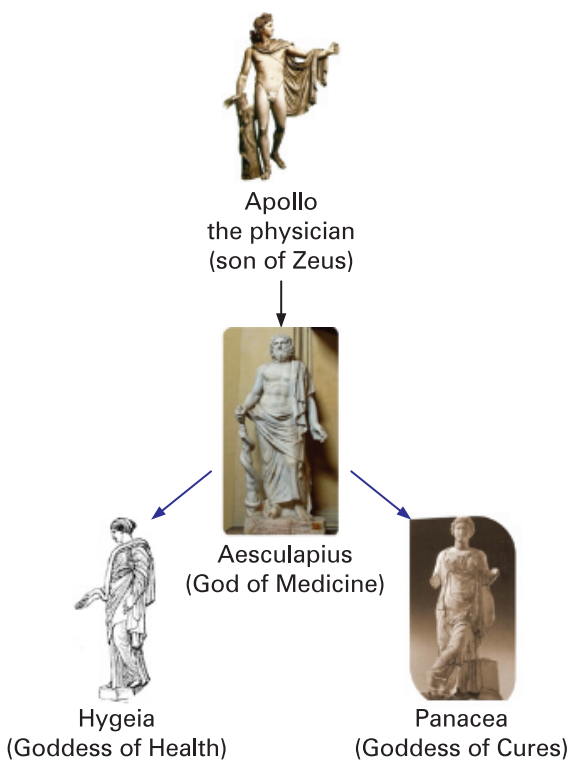

Figure 1 Ancient healthcare management.
W Goethe and the Humboldt brothers, was primarily a physician. However, the burden of war and his duties as a war surgeon were beyond his tolerance so he started a second academic career as a philosopher. At his highly commended inauguration speech at the University of Jena on 26 May 1789 he formulated the aims and objectives of science: "Science should be creative, innovative and searching for efficient and if possible simple solutions for complex problems". Taking Schiller's definition into the present day context could mean maintaining health against the complex background of communicable and non-communicable diseases. Politicians and healthcare providers are united in one answer. There is insufficient money globally to cover the costs for cure (Panacea), particularly because of the advancement of medicine and science (in compliance with the Hippocratic Oath), considering the increasing average age of the world's population. Therefore, the focus of physicians' and scientists' attention should be prevention (Hygeia) and whenever possible, searching for simple solutions for this complex problem (Dvorak, 2007, address to UNESCO in Paris).

Albert Einstein, former professor of mathematics and physics at the Universities of Prague (Czech Republic), Bern and Zurich (Switzerland) and Princeton (United States), supported the philosophies of Hippocrates and Schiller when stating in his emotional speech at the NBC following the dropping of the atomic bombs on Hiroshima and Nagasaki: "The intelligent can solve the problems, the genius will prevent their occurrence".

\section{EXAMPLE OF NON-COMPLIANCE WITH SCIENTIFIC RESULTS}

Musculoskeletal disorders are the most common cause of chronic incapacity in industrial countries. Chronic low back pain (cLBP) is a disability increasing faster than any other form of incapacity. In addition to personal suffering, this causes an enormous financial burden on healthcare systems around the globe. It has been hypothesised that regular exercise (a relatively inexpensive and easily administered therapeutic approach) could be applied to tackle the increasing incidence of low back pain. In a prospective clinical trial $^{2}$ patients with cLBP were randomly assigned into three groups that received twice weekly for 3 months either state of the art physiotherapy, training on specially designed high-tech devices or performing aerobic exercises in a group. The 
authors of this well-designed and wellexecuted study concluded that all three treatments were equally effective in reducing the intensity and frequency of pain and disability. However, the group using aerobic exercises showed better compliance at 12-months' follow-up. The authors calculated the total costs associated with each of the 3-month programmes for 400000 patients with cLBP in Switzerland (where the study was performed). They concluded that if patients with cLBP undertook a programme of aerobic exercise rather than receiving regular physiotherapy or completing exercises on specially designed machines, the outcomes would be similar but there could be potential savings of between 270 and 330 million Swiss francs per year (fig 2).

I imagined that these results would have far-reaching implications for the management of cLBP that healthcare providers the world over could simply not afford to ignore! The study was also well received by the scientific community and was awarded the prestigious Volvo award by the International Society for the Study of the Lumbar Spine (1999). However, despite the enthusiasm of the scientific community, the healthcare providers did ignore the results and even in Switzerland nothing really happened. This begs the question, why not? It could be related to the issue of insurance policies, inappropriate incentives or just ignorance of the facts and figures. Nevertheless, physicians and scientists still believe in prevention, so the question is "how should we communicate and implement scientific results related to prevention?".

\section{MEDICAL SCIENCE AND FOOTBALL}

FIFA (Federation International de Football Association) was established in 1904 and

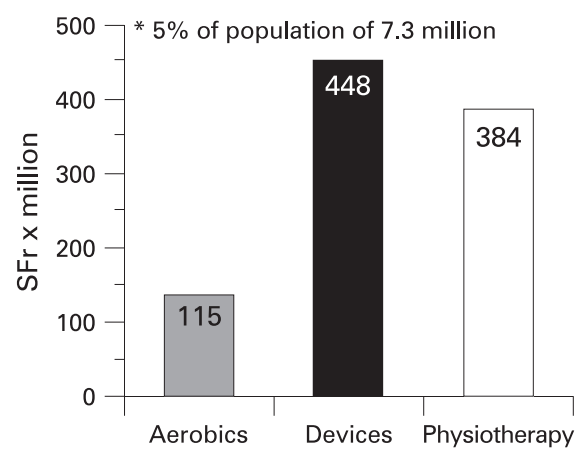

Figure 2 Calculated total costs in Switzerland for each 3-month programme. SFr, Swiss francs. currently has 208 member associations from around the world; there are 260 million active, registered, football players, referees, coaches, medical and paramedical personnel as well as administrators. Hundreds of thousands of organised matches are played every weekend around the globe.

Mr JS Blatter, the FIFA president since 1998, realised that FIFA, as the governing body, bears a huge responsibility for the football community and consequently health issues have become a solid pillar in the development of the game. $\mathrm{Mr}$ Blatter deserves credit for his far-reaching decision to establish a Medical Assessment and Research Centre within FIFA (F-MARC), when awareness of the issue of prevention was almost nonexistent within international sports federations. Mr Blatter, as secretary general of FIFA at the time, presented physicians and scientists with a very simple question: "What can medical science do to improve the game of football and how can the frequency of football injuries and related symptoms be reduced among male and female players at all levels?". FMARC was established in Zurich in 1994 with the aim of providing scientific evidence and knowledge to address various medical problems within football, to reduce or prevent football injuries and to promote football as a health-enhancing leisure activity. While searching through the body of knowledge and references, over 600 papers were identified in 1994, the vast majority of which had a surgical content; only two papers dealt with epidemiological data and only one paper focussed on the prevention of football injuries. Using the data available at that time, it was assumed that each football player sustained one injury per year. Multiplying the number of registered players at that time (200 million) by the average medical cost per case (US\$150), it was estimated that US $\$ 30$ billion were spent annually on the primary care of football-related injuries. It was hypothesised that a reduction of injuries by just $10 \%$ could lead to a significant worldwide reduction in social and economic costs. The logical consequence was to focus FMARC's research activities on prevention.

The entry point for preventive measures was identified as follows:

- The adaptation of the laws of the game (International Football Association Board) to reduce or eliminate the incidence of events occurring in football with the highest propensity to cause injuries.
- Optimal preparation of players for the season and for individual games.

- Pre-season/competition medical assessment.

- Appropriate and state of the art management of injuries by education.

- To convince the administrators and executives within football about the role of medicine in the development of the game and the philosophy of Hippocrates "primum non nocere".

The design of the new research programme was based on the risk management model of Fuller (fig 3).

Because epidemiological data were far from complete and were inconclusive, epidemiological studies were performed on recreational and professional football players of both sexes ${ }^{5} 6$ to allow statistical analysis of risk factors that could lead to injuries.

Critical data analysis quickly revealed that retrospectively acquired data related to injuries and physical symptoms were unreliable and therefore unacceptable for designing preventive programmes. ${ }^{57}$ Epidemiological studies were thus designed with an initial baseline examination and weekly follow-ups throughout 1 year by specially trained physicians. This prospective study allowed an analysis of the individual profiles of football players and injuries, including those requiring medical attention and those causing physical symptoms without the need for medical attention. This definition: "any tissue damage caused by football regardless of subsequent absence from games or training sessions" "was adapted, as a consequence of the results obtained from a number of different studies, and published as a consensus statement at a later stage. ${ }^{8}$ The different aspects of the epidemiological studies were presented as a supplement in the American Journal of Sports Medicine 2000 with the title "Incidence and risk factors of injuries in football players". The results of the 1-year survey documented 2.1 injuries per player per year and allowed us to calculate the impact of a range of risk factors.

At the FIFA World Cup 1998 in France, a prospective injury surveillance study was initiated to register every injury that occurred during a FIFA tournament; this was based on an injury questionnaire completed by team physicians. The team physicians understood the importance of answering the research questions underpinning this large prospective survey, and this resulted in excellent collaboration and a high level of compliance for this ongoing study since 1998. In that period, 36 FIFA 


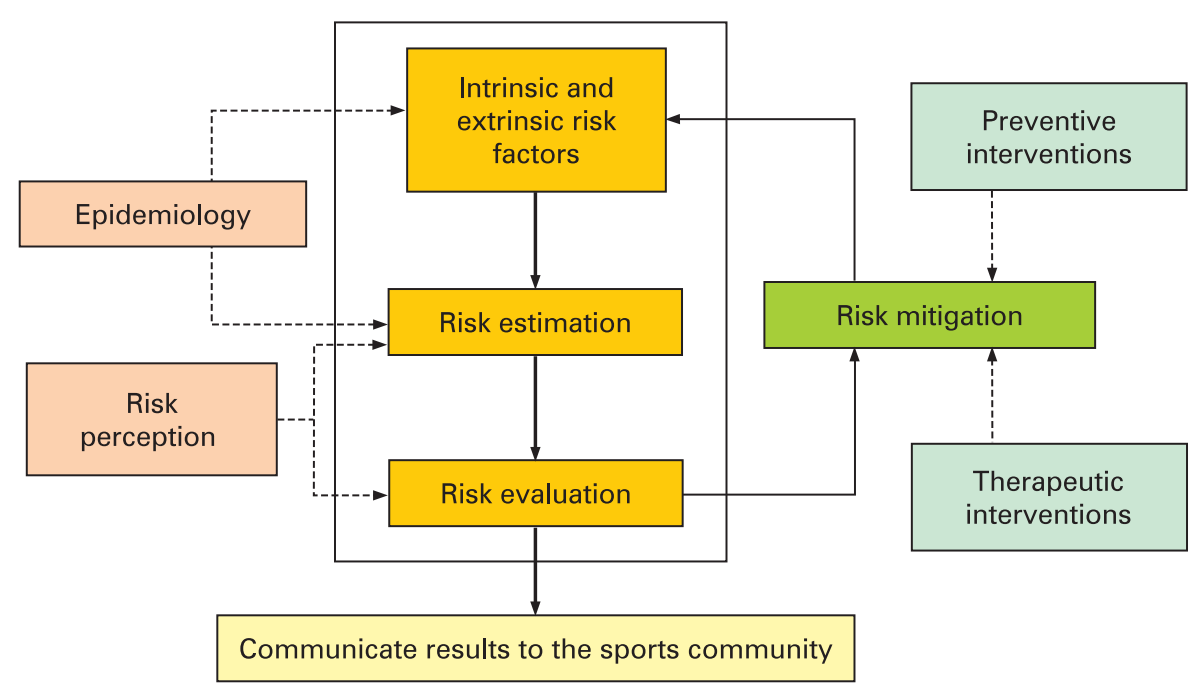

Figure 3 Risk management model, Fuller. ${ }^{4}$

competitions have been surveyed, allowing us to analyse 2796 injuries that occurred in 1133 matches (or 35344 individual player hours); these matches include three consecutive men's and women's FIFA World Cups and three consecutive Olympic Games. Over these 36 competitions, there have been, on average, 2.7 injuries per match or 79 injuries per 1000 playing hours (figs 4, 5 and 6).

The data available on injuries sustained during FIFA competitions offered a unique opportunity to analyse the cause of injuries using video sequences. The results of this extensive analysis, together with 10 other research projects, were published in a second supplement of the American Journal of Sports Medicine with the title "Incidence and causation of injuries in football". As a result of examining the influence of tackle parameters on the propensity for injury in international football, ${ }^{9}$ it was concluded that the laws of the game related to tackling should be reviewed to provide players with greater protection from injury by reducing the overall level of risk and specifically protecting players from those tackles that have the highest propensity for causing injuries. The incidents with highest injury risk were identified as tackling from behind (which became punishable with a red card and has almost been eliminated from the game), the twofooted sliding tackles from the front and side and the elbow to head that occurs during aerial combat. The latter type of incident was examined using biomechanical analysis and experiments with

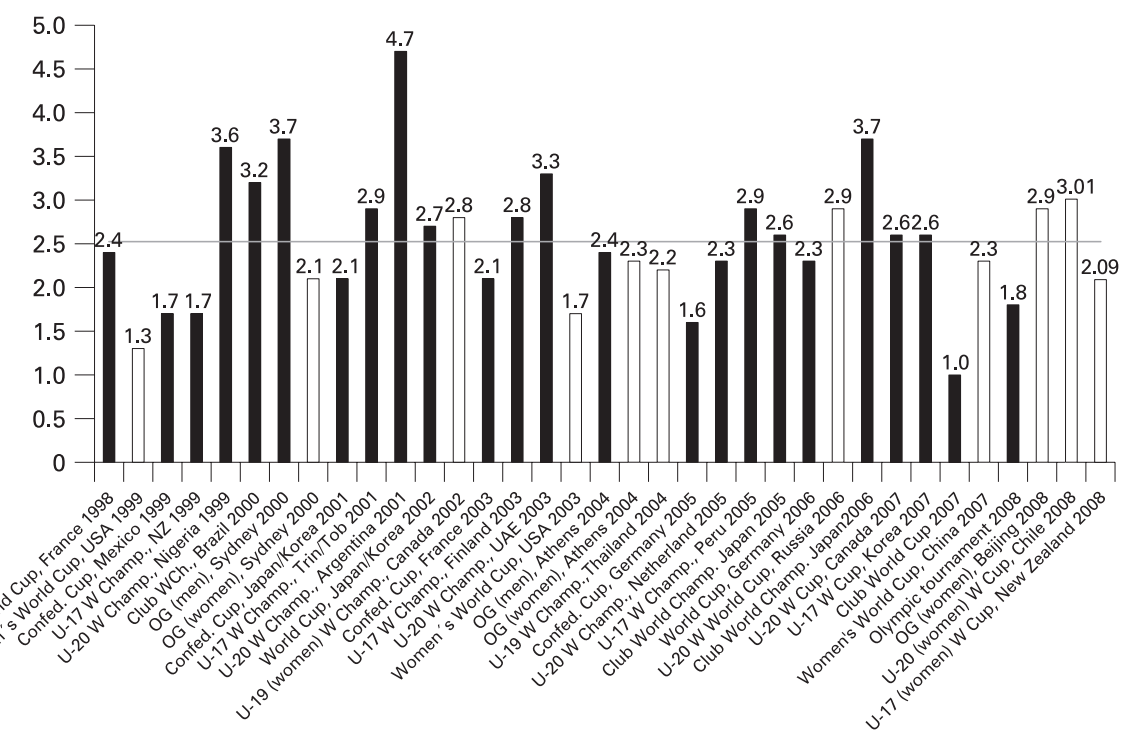

Figure 4 Injuries per match. human surrogates to simulate the incidents and to calculate the biomechanical forces exerted on the head and brain. The results obtained from the research studies performed in biomechanical laboratories in Ottawa, Canada (Biokinetics) were published alongside results from a number of other studies in a third supplement from F-MARC in the British Journal of Sports Medicine that focused on head injuries in football. The conclusions from the 10 papers on head injuries were presented to the International Football Association Board, which considered the evidence and decided that the particular incident of elbow to the head (fig 7) should be sanctioned with a red card. The consequent application of this decision during the 2006 FIFA World Cup proved to be efficient, and head injuries and concussion were reduced in comparison with the previous World Cup (fig 8).

\section{DEVELOPMENT OF PREVENTIVE PROGRAMMES TO REDUCE FOOTBALL INJURIES}

Based on the risk factor analysis ${ }^{5}$ and studies $^{10}$ offering evidence for reducing football-related injuries, as well as best practice, a group of experts outlined a preventive programme consisting of 10 simple exercises linked with fair play: "The 11". This programme aimed to reduce the most common injuries, such as ankle and knee ligament sprains and thigh and groin muscle strains. "The 11" were presented on the FIFA web page (www.FIFA.com/medical) as well as in the F-MARC football medical manual. The preventive programme, which was directed primarily at amateur and recreational players, focuses on core stability, eccentric training of tight muscles, proprioception, balance training and plyometrics. The programme was designed to be completed within the 10-15 minutes normal warm-up period. Together with the national health insurance company and the football association, the prevention programme was implemented as a country-wide campaign in Switzerland, New Zealand and the Czech Republic. In Switzerland, a well-designed research project was conducted to analyse the effects of the campaign. The results showed impressively that football injuries could be reduced even on a nationwide level.

Detailed analysis of the implementation of "The 11" indicated that compliance could be increased by including progression within the different exercises over the course of a training season. Following the experience with the preventive programme Prevention Enhances 


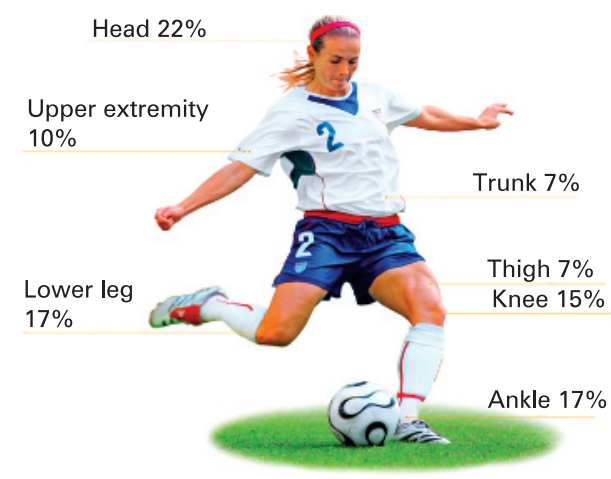

Figure 5 Injuries related to body part.

Performance and "The 11", a comprehensive warm-up programme "The 11+" was developed; this advanced programme started and ended with structured running exercises and included six exercise types for strength, balance and jumping, each with three levels of difficulty. "The $11+$ " can be performed in 20 minutes, as part of a regular warm-up before every training session, at least twice a week. In a cluster randomised controlled trial performed in collaboration with the Oslo Sports Trauma Research Centre (Norway), "The 11+" was evaluated for its efficacy to prevent football injuries. A total of 2540 female players was randomly assigned into intervention and control groups. The intervention group underwent "The 11+" programme throughout one season while the control group continued their usual warm-up. The team coaches were instructed on the programme and received appropriate educational materials; all injuries were registered according to the consensus statement definition for injuries. ${ }^{8}$ The

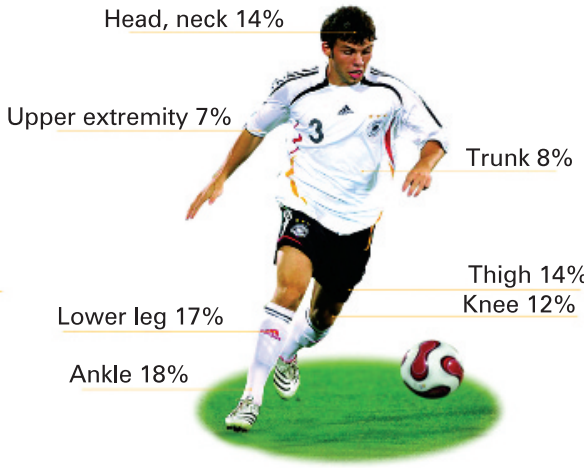

results can be summarised in a simplified but valid statement: "The higher the compliance with "The 11+" programme the fewer injuries will occur' (fig 9). In the intermediate and high compliance groups the reduction in the incidence of injuries was between $30 \%$ and $50 \%$; in particular, severe injuries to lower extremities were reduced. The authors concluded in the landmark publication in the British Medical Journal" that "The 11+" reduced injury risk in female youth football players, and that "The 11+" should be a core element of coach education and training programmes in this group.

\section{FIFTEEN YEARS OF F-MARC: WHAT HAS BEEN ACHIEVED?}

The epidemiological data on injuries at different levels of play for male and female players allowed the analysis of risk factors and provided the background information for preventive programmes for football players called "The 11" and "The 11+". As outlined above, the "The

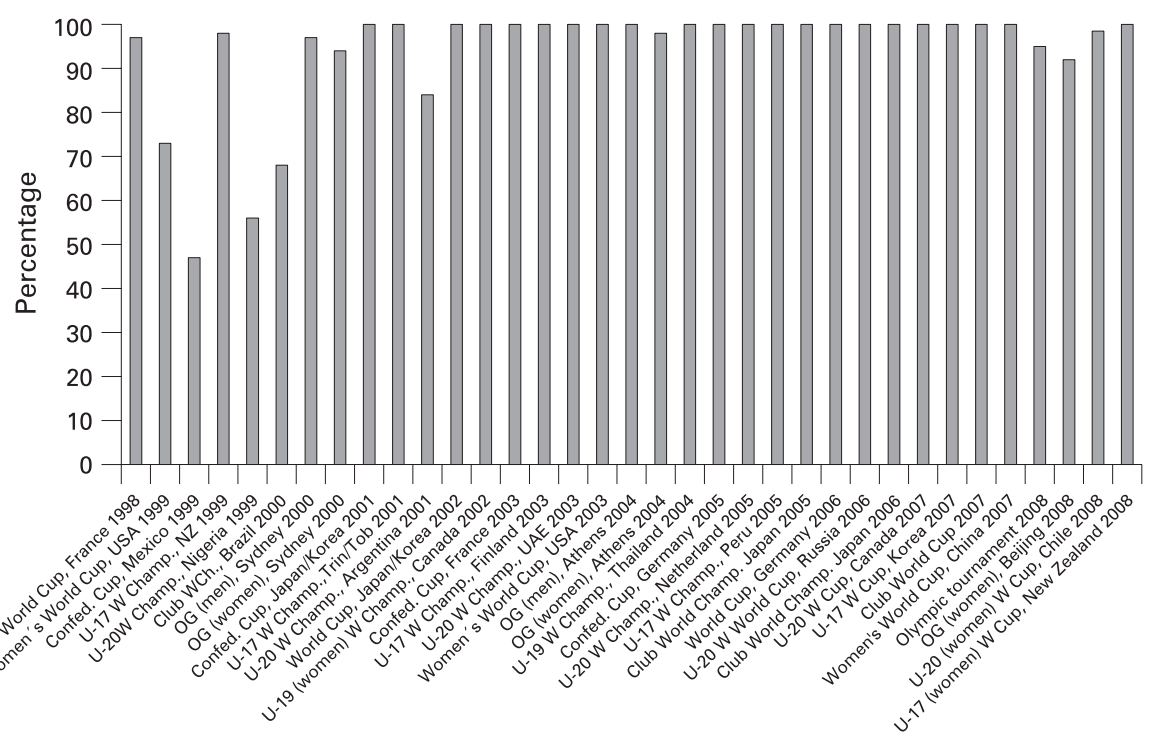

Figure 6 Return rate of injury report forms (compliance of team physicians).

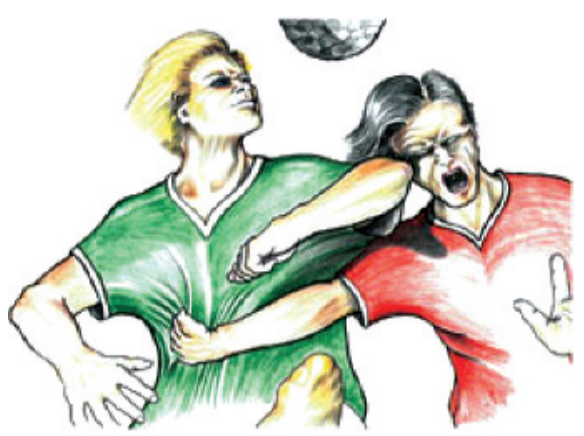

Figure 7 Elbow to head injury mechanism (red card). Reproduced with permission from Bolic. ${ }^{12}$

$11+$ " programme reduced injury rates by $30-50 \%$, depending on the level of compliance. A nationwide implementation of "The 11" programme in Switzerland from 2004 to 2008 resulted in a 10\% overall reduction in the level of injuries among football players. The hypothesis outlined by F-MARC in 1994 proved to be valid: science and medicine does offer the world of football remedies to reduce the occurrence of injuries and these remedies have the potential to save billions of dollars in injury costs. Also, the reduction of injuries in high-profile matches has been achieved by adaptation and application of the laws of the game through the philosophy of fair play.

Recent studies performed by a Danish group $^{13}$ documented that playing regular football by members of an unfit population not only improves physical fitness but also reduces cardiovascular risk factors, such as borderline blood pressure, elevated cholesterol and glucose as well as body mass index. Summarising the different studies, there is scientific evidence that football can be promoted as a healthenhancing leisure activity. The published F-MARC studies justify the recently adopted F-MARC logo "Football for Health" (fig 10), because, in the long term, football can reduce or prevent the risks of many chronic diseases as concluded by Booth and Roberts. ${ }^{1}$

\section{COMMUNICATION, IMPLEMENTATION, COLLABORATION}

The scientific studies clearly documented that the higher the compliance the better the results related to injury incidence. Bearing in mind the estimated primary medical costs caused by football-related injuries, it is clear that the scientific evidence can only impact on the social and economic environments around the globe if the results are implemented within the football community. FMARC has developed a network of 


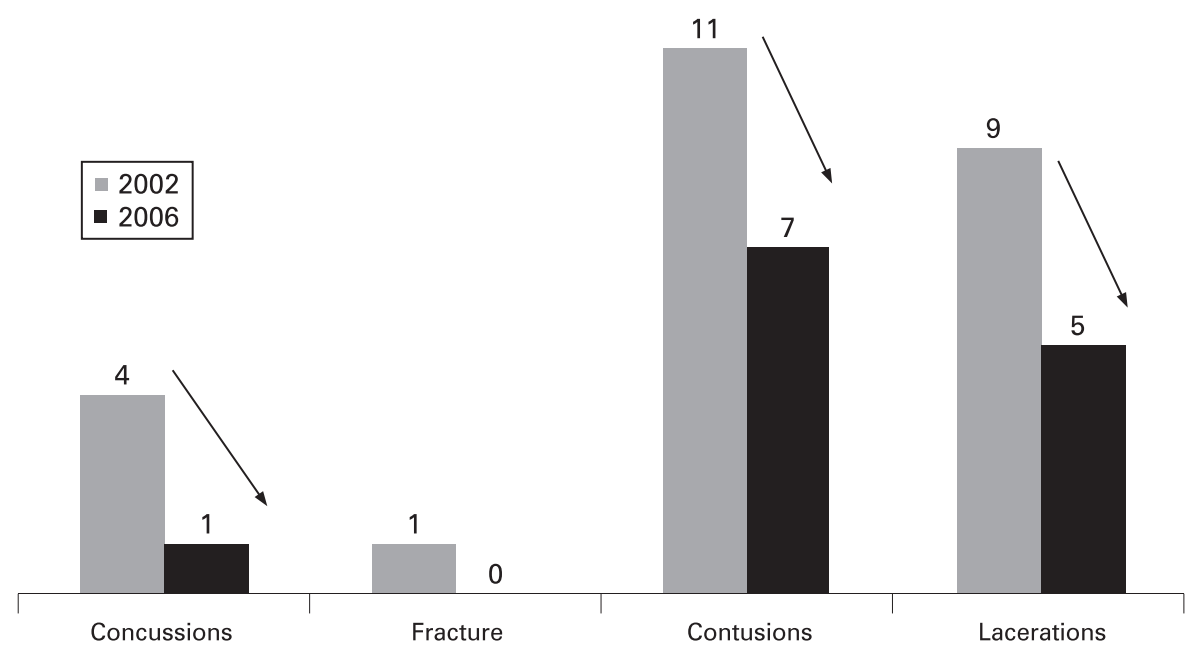

Figure 8 Head injuries during the 2002 and 2006 FIFA World Cups.

medical officers to implement the scientific findings within the respective member associations. The members of the network are recruited within the worldwide education programme Futuro III (www.FIFA.com/medical). Also, FIFA medical centres are continuously accredited in different countries of the member associations as centres of excellence for football medicine, with documented experience, knowledge and scientific activities to serve as regional centres for the implementation, development and performance of future studies. To date, nine centres have been established (Zurich, Auckland, Santa Monica, Johannesburg, Cape Town, Tokyo, Munich, Regensburg and Doha). Also, member associations are regularly updated about the most recent scientific studies and the role of medicine in developing the game through the annual FIFA Congress, which regularly provides member associations with the opportunity to present results from interventions in their countries. Later in 2009, FIFA will sponsor a medical network conference, which will be attended by the president and general secretary as well as the team physician of each member organisation. This conference, which is the first major event to be organised by an international sports federation for both top executive sports administrators and doctors, will be used to launch the worldwide F-MARC initiative "Football for Health".

Over the course of the past 15 years, excellent collaborations have been established in countries throughout the world, not only with academic institutions but also with other international sporting organisations. In particular, the collaboration of the medical representatives of the international team sports federations proved to be extremely fruitful in addressing common problems, such as preventing and managing injuries and developing and implementing strategies in the fight against doping. During the Olympic Games 2004 in Athens, the F-MARC injury surveillance system was used by all team sports to collect injury data. ${ }^{14}$ This study was the starting point in increasing collaboration with the International Olympic Committee Medical Committee and the International Olympic Committee Medical Research Group. Following the positive experience at the Olympic Games 2004 and a successful pilot study during the International Association of Athletics Federations World Championships in Osaka 2007, the injury surveillance study was expanded to cover all sports at the Beijing Olympics in 2008. ${ }^{15}$ In this respect, it has been proved that science and sport can work together towards a mentally and physically healthier society, and this example is absolutely consistent with a recently published statement by Tapscott and Williams ${ }^{16}$ who argued for the importance of "openness, sharing, peering and acting globally".

Given this current position, the FMARC team is in the process of using the popularity of football worldwide as a platform to disseminate simple educational messages for youth male and female football players to tackle noncommunicable (high blood pressure, obesity and diabetes among others) and communicable (tuberculosis, malaria and AIDS_ "the big three") diseases. These diseases are serious threats for the African population, so the activities of F-MARC are focused on the African continent while preparing for the FIFA World Cup 2010 in South Africa: a continental initiative: Football for Health in Africa, ie, win in Africa, with

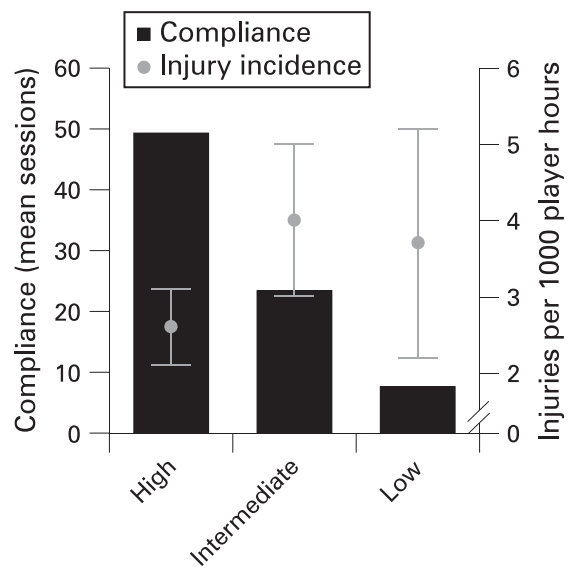

Figure 9 Compliance and injury risk.

Africa. Consultation with relevant nongovernmental organisations and other experts resulted in the "11 for Health in Africa"-11 messages to be included as a part of training sessions of football teams. A pilot study was launched in the informal dwellings of Cape Town in March 2009; if succesful, an Africa-wide roll-out of the programme is planned at the time of the 2010 World Cup.

Over 15 years, medicine offered services to FIFA to improve the game, now we have asked FIFA to use their logistics, infrastructure and network to try to improve the health situation wherever possible.

From "Medicine for Football" to "Football for Health". The answer was-"Yes, do it".

Acknowledgements: The author would like to thank PD Dr Astrid Junge and Professor Colin Fuller for their intellectual input and continuous research activities within F-MARC over the past 10 years and the careful review of this paper, and Mr JS Blatter, president of FIFA, for his honest support of medicine and science to maintain and improve the health of

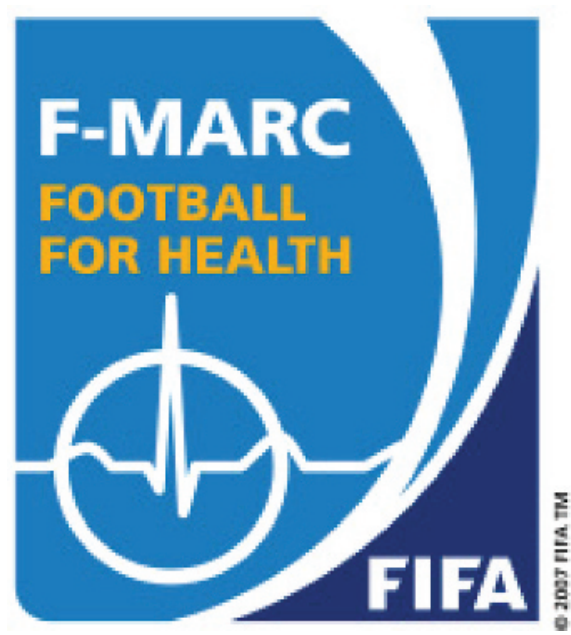

Figure 10 F-MARC “Football for Health" logo. 
football players, from the very beginning of F-MARC, when many were reluctant. The author also thanks the members of the FIFA Medical Committee, in particular the chairman, Dr Michel D'Hooghe, for support and collaboration in the different parts of the football world. This paper is dedicated to young sports physicians and scientists.

Competing interests: None.

This paper is based on the "Give Hippocrates a jersey - promoting health through sports (football)" keynote lecture at the 2nd International Conference on the Prevention of Injuries in Sports. Tromso, Norway, June 2008.

Accepted 3 March 2009

Published Online First 22 March 2009

Br J Sports Med 2009;43:317-322.

doi:10.1136/bjsm.2009.059618

\section{REFERENCES}

1. Booth FW, Roberts CK. Linking performance and chronic disease risk: indices of physical performance are surrogates for health. $\mathrm{Br} J$ Sports Med 2008;42:950-2.
2. Mannion AF, Muntener M, Taimela S, et al. A randomized clinical trial of three active therapies for chronic low back pain. Spine 1999;24:2435-48.

3. Ekstrand J, Gillquist J. Soccer injuries and their mechanisms: a prospective study. Med Sci Sports Exerc 1983;15:267-70.

4. Fuller CW. Managing the risk of injury in sport. Clin J Sport Med 2007;17:182-7.

5. Dvorak J, Junge A, Chomiak J, et al. Risk factor analysis for injuries in football players. Possibilities for a prevention program. Am J Sports Med 2000;28(5 Suppl):S69-74.

6. Junge A, Chomiak J, Dvorak J. Incidence of footbal injuries in youth players. Comparison of players from two European regions. Am J Sports Med 2000;28/5 Suppl):S47-50.

7. Junge A, Dvorak J. Influence of definition and data collection on the incidence of injuries in football. Am J Sports Med 2000;28(5 Suppl):S40-6.

8. Fuller CW, Ekstrand J, Junge A, et al. Consensus statement on injury definitions and data collection procedures in studies of football (soccer) injuries. Br J Sports Med 2006;40:193-201.

9. Fuller CW, Smith GL, Junge A, et al. The influence of tackle parameters on the propensity for injury in international football. Am J Sports Med 2004;32(1 Suppl):43S-53.
10. Junge A, Rosch D, Peterson $L$, et al. Prevention of soccer injuries: a prospective intervention study in youth amateur players. Am J Sports Med 2002;30:652-9.

11. Soligard T, Myklebust G, Steffen K, et al. Comprehensive warm-up programme to prevent injuries in young female footballers: cluster randomised controlled trial. BMJ 2008;337:a2469.

12. Bolic T. Clinical guide to sports injuries: an illustrated guide to the management of injuries in physical activity. Leeds: Human Kinetics, 2004

13. Krustrup P, Nielsen JJ, Krustrup B, et al. Recreational soccer is an effective health promoting activity for untrained men. Br J Sports Med. Published Online First: 14 December 2008. doi: 10.1136/ bjsm.2008.053124.

14. Junge A, Langevoort G, Pipe A, et al. Injuries in team sport tournaments during the 2004 Olympic Games. Am J Sports Med 2006;34:565-76.

15. Alonso JM, Junge $A$, Renstrom $P$, et al. Sports injuries surveillance during the 2007 IAAF World Athletics Championships. Clin J Sport Med 2009; 19:26-32.

16. Tapscott D, Williams A. Wikinomics: how mass collaboration changes everything. London: Portfolio, 2008 . 